\section{B-cell lymphoma with bowel-to-bowel penetration diagnosed by double-balloon endoscopy}

A 52-year-old male patient was admitted because of diffuse abdominal pain and weight loss during the previous 6 months. Recent investigations, including an abdominal computed tomography scan and laparoscopy, revealed no pathologic findings. The laboratory results showed pathologic findings for iron deficiency anemia (hemoglobin $12.6 \mathrm{~g} / \mathrm{dL}$, iron $74 \mu \mathrm{g} / \mathrm{dL}$ ), and slight elevation of the C-reactive protein $(1.1 \mathrm{mg} / \mathrm{dL})$. Beside the above mentioned symptoms, the patient denied further health problems or use of any medication.

An abdominal ultrasound was normal; however, magnetic resonance enteroclysis revealed in the jejunum, a bowel segment with transmural wall swelling, compatible with Crohn's disease of the jejunum. Because of the diagnosis of suspected Crohn's disease, with exclusive manifestation in the jejunum, capsule endoscopy was performed. The capsule reached the proximal jejunum without showing any pathologic results; video sequences showed little movement of the capsule and revealed stool contamination and mucosal swelling ( Video 1 ). Here, no classic signs of mucosal findings for Crohn's disease were observed. The capsule did not reach the cecum after 8 hours of recording time, but was excreted later in the stool.

A push-and-pull-endoscopy revealed a large cavity filled with stool at approximately $200 \mathrm{~cm}$ postpylorus. After washing, this cavity showed three openings, one with a short stenosis and normal mucosa beyond the stenosis. The mucosa in the large cavity showed pathologic findings with edema, erythema, inflammation, and ulceration ( Figures $\mathbf{1} \mathbf{a}-\mathbf{d}$ ). Intubation of the two other lumina was only possible for a few centimetres; instillation of radiopaque material revealed a blind end.
The pathologic report of the biopsies showed infiltration by a diffuse nonHodgkin's B-cell lymphoma. Surgery confirmed the diagnosis and showed a large bowel-to-bowel-penetration by the lymphoma. In summary, this case demonstrated the rapid diagnosis of the first manifestation of a B-cell lymphoma of the bowel by double-balloon endoscopy.

Endoscopy_UCTN_Code_CCL_1AC_2AC

\section{Schäfer, B. Razziourrouh, \\ H. Diepolder, B. Göke}

Department of Internal Medicine II, Klinikum Grosshadern, Ludwig-Maximilian-University Munich, Germany

\section{Bibliography}

DOI $10.1055 / s-2007-966425$

Endoscopy 2007; 39: 204

(c) Georg Thieme Verlag KG Stuttgart · New York . ISSN 0013-726X

\section{Corresponding author}

\section{Schäfer, MD}

Department of Internal Medicine II

Klinikum Grosshadern

Ludwig-Maximilian-University Munich

Marchioninistr. 15

D-81377 Munich

Germany

Fax: +49-89-70956183

Claus.Schaefer@med.uni-muenchen.de

\section{Video 1}

Capsule endoscopy showed stool contamination and mucosal swelling, raising the suspicion of stenosis. Note that no tumor signs are seen here.

online content including video sequences viewable at:

www.thieme-connect.de/ejournals/abstract/ endoscopy/

doi/10.1055/s-2007-966425
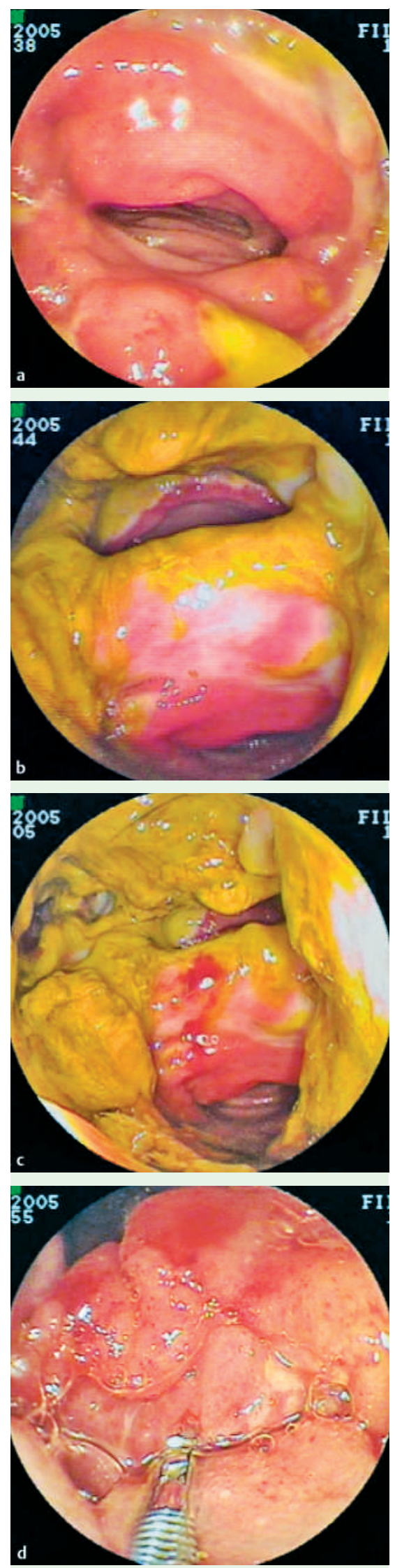

Figure 1 a-d Push-and-pull endoscopy revealed at $200 \mathrm{~cm}$ post pylorus a short stenosis followed by a large cavity, which was histologically confirmed as a diffuse B-cell lymphoma. 